This item was submitted to Loughborough's Research Repository by the author.

Items in Figshare are protected by copyright, with all rights reserved, unless otherwise indicated.

\title{
Evaluation of the Right2BCared4 pilots: final report - research brief
}

PLEASE CITE THE PUBLISHED VERSION

https://www.gov.uk/government/uploads/system/uploads/attachment_data/file/192965/DFE-RB106.pdf

\section{PUBLISHER}

Department for Education, London

\section{VERSION}

VoR (Version of Record)

\section{PUBLISHER STATEMENT}

This work is made available according to the conditions of the Creative Commons Attribution-NonCommercialNoDerivatives 4.0 International (CC BY-NC-ND 4.0) licence. Full details of this licence are available at: https://creativecommons.org/licenses/by-nc-nd/4.0/

\section{LICENCE}

CC BY-NC-ND 4.0

\section{REPOSITORY RECORD}

Munro, Emily R., Clare Lushey, and Harriet Ward. 2019. "Evaluation of the Right2bcared4 Pilots: Final Report - Research Brief". figshare. https://hdl.handle.net/2134/18376. 


\section{Research Brief}

DFE-RB106

ISBN 978-1-84775-897-2

May 2011

\section{Evaluation of the Right2BCared4 Pilots: Final report}

\section{Emily R. Munro*, Clare Lushey*, Harriet Ward* and National Care Advisory Service ${ }^{*}$ Centre for Child and Family Research, Loughborough University}

\section{INTRODUCTION}

The Right2BCared4 pilot began in October 2007 in 11 local authorities and is based on the following principles:

- Young people should not be expected to leave care until they reach 18 years of age;

- They should have a greater say in the decision making process preceding their exit from care; and

- Should be properly prepared for living independently.

Key to this pilot is that the transition from care to independence should be planned and properly managed, that young people should be consulted about their wishes and feelings and should have access to independent advocacy.

Right2BCared4 is not a single intervention, instead it has allowed pilot authorities to improve practice to promote the welfare of young people making the transition to adulthood. The pilot was undertaken at a time of rapid policy development in relation to leaving care services, with local authorities developing policy and practice in response. The findings from the evaluation demonstrate that the comparator authorities are generally operating in line with the principles of Right2BCared4. In this sense the research offers an insight into current good practice and illuminates how authorities might deploy their existing resources to best effect to meet their existing statutory duties.

\section{KEY FINDINGS}

- There has been a cultural shift in professional attitudes concerning care planning and decision-making for young people aged 16 years and over; professionals have become more proactive in encouraging young people to remain looked after until legal adulthood. A higher proportion of those in the pilot authorities were looked after until they reached legal adulthood compared to those from comparator authorities.

- Professionals identified that not all young people want to remain in care for longer. White British young women, especially parents, tend to leave care early. Those who have experienced multiple placement changes (often due to complex needs) are also likely to leave care early. It is important that packages of support are available to meet the needs of those who choose to move to independence.

- The majority of care leavers surveyed said that it was their choice to leave care. The figures reveal that a slightly higher percentage of those in the pilot authorities felt that they had had a choice about when they left compared to those from comparator authorities; $62 \%$ and $52 \%$ respectively.

- Over half of those who moved into semi-independent or independent living arrangements were positive about their transitions. Around a quarter identified that 
the process of transition could have been improved and that moves had been rushed and abrupt.

- Young people generally felt involved in the pathway planning process. However, certain issues, including young people's relationships with their birth families and health needs, received minimal attention.

- Young people are entitled to remain in care until they reach 18 but historically they have not always been encouraged to do so, even when this would have been in their best interests. The national estimated cost of keeping all 16 to 17 year olds in care for a year longer is $£ 212.8$ million.

\begin{abstract}
AIMS
The overarching aim of the evaluation was to assess the extent to which the Right2BCared4 pilots help care leavers achieve better outcomes. The evaluation examines the extent to which the Right2BCared4 pilots have:

- Empowered young people to participate meaningfully at each stage of the transition process;

- Enhanced communication and relationships between social workers/independent reviewing officers (IROs) and young people;

- Implemented robust review mechanisms that ensure care and pathway plans reflect the needs and wishes of young people;

- Improved the stability of final care placements and reduced the number of young people moving to independence before reaching aged 18;

- Provided additional benefits and improved outcomes compared to more standard leaving care services.
\end{abstract}

The evaluation also involved assessment of the relative costs of operating Right2Bcared4 as compared with those of operating a standard leaving care service and explored the cost implications for local authorities.

\title{
METHODOLOGY
}

A mixed methods approach was adopted. A mapping exercise and focus groups involving social workers, leaving care personal advisers, Independent Reviewing Officers (IROs) and other key professionals was undertaken in 11 pilot sites (see Munro et al., 2010a for the main findings from this aspect of the evaluation). In-depth work was then conducted in seven pilot authorities and two comparator (non-pilot) authorities, including:

- A baseline survey of 184 young people (133 from pilot authorities and 51 from comparator authorities) and a follow-up survey of 41 young people (28 from pilot authorities and 13 from comparator authorities);

- Face to face interviews with 33 young people (25 from pilot authorities and 8 from comparator authorities);

- Scrutiny of the case records of 21 young people (13 from pilot authorities and 8 from comparator authorities);

- Telephone interviews with 16 leaving care personal advisers and/or social workers; seven IROs and two advocates;

- Face to face interviews with six managers responsible for the delivery of Right2BCared4;

- Twelve focus groups and two interviews involving social workers, leaving care personal advisers, IROs and advocates in two pilot and two comparator authorities to collect 'time spent activity' data for the costing exercise. Verification questionnaires were also completed by 37 children's social care professionals. 
The local authorities involved in the pilot were expected to meet the criteria for Beacon status and comparator authorities were purposively selected on the basis that they were identified as providing best 'standard leaving care' practice; as such, the findings should not be viewed as representative of current leaving care provision across England. In interpreting the study findings it should also be noted that in comparison to the general looked after children population, the interview sample consisted of a higher proportion of young women than men and a high proportion of young mothers.

\section{FINDINGS}

Young people's entitlement to remain in care until they reach legal adulthood and the right to return

- Professionals reported a change in culture, with an increased emphasis being placed upon young people's entitlement to stay in care for longer. A higher proportion of those in the pilot authorities were looked after until they reached legal adulthood compared to those from comparator authorities.

- Challenges were sometimes experienced by professionals trying to sustain placements as this was conditional not only on the young person wanting to stay, but also on foster carers or residential units being willing and able to continue the placement (see also, Munro et al., 2010a; 2010b).

- Under Right2BCared4 young people are offered the option to return to care if they left before the age of 18 and encountered difficulties. This was seen to offer a 'safety net' and replicated normative experiences. However foster care shortages meant that it was rarely possible for a young person to return to their previous placement.

- Four fifths of survey respondents said that they thought young people should be permitted to return to care if they want to, yet only one survey respondent had done so. A small number were unable to return because an appropriate placement could not be identified or because the young person had reached legal adulthood.

\section{Pathway planning and review}

- Scrutiny of case records revealed deficits in the quality of recording on pathway plans. Over two thirds failed to record information on needs in relation to identity; support from birth family, carers or the responsible authority; and family and environmental factors. Data on young people's education, training and employment were the most comprehensive.

- The majority of young people surveyed felt 'very' or 'quite' involved in the preparation of their pathway plan. The percentage was higher in comparator authorities than pilot authorities; 93\% (38) and 80\% (85) respectively.

- Young people valued plans that explored how their current circumstances might change, when goals were set and when it was clear what services the local authority would supply to support them in making the transition to adulthood.

- Young people reported that delays in completion of plans, or failure to review and update them, undermined their relevance.

- Most young people (71\%) reported that they were always encouraged to express their wishes and feelings at review meetings; however, only $53 \%$ felt they were always listened to.

- Around two thirds of young people $(62 \%, 111)$ were in favour of additional reviews when significant changes were proposed, signalling their desire to be involved in decision making. However, findings from interviews revealed that the review meeting itself could inhibit their active participation if it involved a large number of professionals. 
The role of Independent Reviewing Officers

- Under Right2BCared4 IROs are required to consult with young people prior to their review to establish their wishes and feelings. Survey data revealed that a higher percentage of young people from the pilot authorities (35\%; 37), indicated that their IRO was involved in discussions around their pathway plans, compared to those in comparator authorities (24\%; 10).

- Survey data revealed a high level of satisfaction with the support offered by IROs. However, findings from the interviews suggest a more varied picture; it was not uncommon for young people to be uncertain about who their IRO was.

- An identified benefit of the enhanced involvement of the IRO was that this afforded young people the opportunity to discuss concerns about their relationship with, or the care provided by their foster parents, with someone who was 'independent' and impartial.

- In-house and out-of-house IRO arrangements both have strengths and weaknesses. What is critical is that IROs are skilled and willing to scrutinise and challenge and that local authorities respond appropriately.

\section{Independent advocacy}

- As part of the pilot a number of authorities sought to promote the use of advocacy services. Just over half $(54 \% ; 67)$ of survey respondents from the pilot authorities indicated that they had been offered the opportunity to see an independent advocate, compared to a slightly lower percentage $(48 \% ; 22)$ of those from comparators. Uptake of the service was also higher in pilot authorities $(62 \% ; 40)$ than in comparators $(41 \% ; 9)$. The majority rated the support they received from their advocate highly.

- Only a small percentage of advocates were involved in supporting young people with the pathway planning process. More young people in the pilot authorities $(12 ; 11 \%)$ indicated that their advocate had been involved than those in comparator authorities $(2 ; 5 \%)$.

\section{Preparation and support}

- Young people were least confident about their abilities to: manage their finances, pay their household bills and claim welfare entitlements. A significant number also spoke of isolation and loneliness.

- The majority of young people rated the support they received from social workers, leaving care personal advisers and carers very highly. Just over two thirds of young people who reported that they received support from their families judged this to be 'OK, good or very good'.

\section{Early outcomes}

- On the whole young people rated their health, emotional wellbeing and confidence highly.

- The education, employment or training (EET) status of the Right2BCared4 cohort was similar to that of former care leavers nationally. A higher percentage of respondents from comparator authorities were in education, work or work based training than their counterparts in pilot authorities. Seventy seven percent of young people (39) from the comparator authorities were in education compared to $63 \%$ (84) in the pilot authorities.

- Respondents who had two or three placements were around four times more likely to be NEET than respondents who had had one placement in the previous three years. This highlights the importance of placement stability in young people's lives. 
Transitions to independence

- Around three fifths $(39 ; 59 \%)$ of care leavers surveyed said that it was their choice to leave care. The percentage was slightly higher in pilot authorities than comparators; $62 \%$ and $52 \%$ respectively.

- Over half of those who moved into semi-independent or independent living arrangements were positive about their transitions. Around a quarter identified that the process of transition could have been improved and that moves had been rushed and abrupt.

- Reasons for changes of accommodation were varied and included 'young person led' decisions, which were influenced by a number of issues including: a desire to be 'free' and 'independent', levels of satisfaction with their placement and relationship with their carers, and wanting to set up home with a partner. Some moves were 'age related' in that young people were approaching or had reached legal adulthood and could no longer stay in their placement. 'Placement breakdowns or multiple' reasons precipitated transitions in a small number of cases.

\section{IMPLICATIONS FOR POLICY AND PRACTICE}

- Not all young people want to remain in care for longer. The reasons for this and approaches that may be employed to encourage them to remain looked after for longer warrant consideration. It is also important that services and support are available to support those who choose to move to independence.

- As young people reach adulthood they may want to reconnect with birth family and many may return to live with family when they leave care. For some young people these relationships will be beneficial and supportive, however, for others they may be damaging (Biehal et al., 1995; Dixon and Stein, 2005; Stein, 2004; Wade, 2008). It is important that social workers and leaving care workers are proactive in exploring family relationships when pathway planning in order to manage young people's expectations and prepare them for renewed or increased contact.

- It is critical that IROs are skilled and willing to scrutinise and challenge and that local authorities respond appropriately.

- Right2BCared4 has not fully resolved difficulties surrounding young people's transitions from care to adulthood, although it may postpone them until young people are slightly older. Some young people continued to experience age related rather than needs led changes in their living arrangements.

\section{CONCLUSION}

Although the number remaining looked after into adulthood is rising it was acknowledge that age related eligibility to remain in care means that some young people continue to leave before they are necessarily ready to do so. Around a third of young people from pilot authorities felt that they did not have a choice about the timing of their transition from care to adulthood and amongst the interview sample there were examples of young people who continued to experience age related rather than young person led moves.

Messages from young people serve to reiterate the central importance of consistent and supportive relationships with social workers and personal advisers to assist them in preparing for and navigating the transition from care to independence.

Overall, realistic assessments and plans, developed in conjunction with young people, alongside effective preparation provide a foundation for planned and supported transitions. Given the diversity in young people's needs and circumstances the level and type of ongoing support they will require once they have left care will vary. 


\section{REFERENCES}

Biehal, N., Clayden, J., Stein, M. and Wade, J. (1995) Moving On: Young People and Leaving Care Schemes. London: HMSO.

Dixon, J. and Stein, M. (2005) Leaving Care: Throughcare and Aftercare in Scotland. London: The Stationery Office.

Munro, E.R., Ward, H., Lushey, C. and National Care Advisory Service (2010a) Evaluation of the Right2BCared4 pilots interim report: overview of emerging themes and issues. London: Department for Education.

Munro, E.R., Maskell-Graham, D., Ward, H. and National Care Advisory Service (2010b) Evaluation of the Staying Put: 18 plus family placement pilot programme interim report: overview of emerging themes and issues. London: Department for Education.

Stein, M. (2004) What Works for Young People Leaving Care? Barkingside: Barnado's.

Wade, J. (2008) 'The ties that bind: Support from birth families and substitute families for young people leaving care.' British Journal of Social Work 38, 39-54. 


\section{Additional Information}

The full report can be accessed at http://www.education.gov.uk/publications/

Further information about this research can be obtained from Paul Denis, Sanctuary Buildings, Great Smith Street, London, SW1P 3BT Paul.DENIS@education.gsi.gov.uk

This research report was commissioned before the new UK Government took office on 11 May 2010. As a result the content may not reflect current Government policy and may make reference to the Department for Children, Schools and Families (DCSF) which has now been replaced by the Department for Education (DFE).

The views expressed in this report are the authors' and do not necessarily reflect those of the Department for Education. 